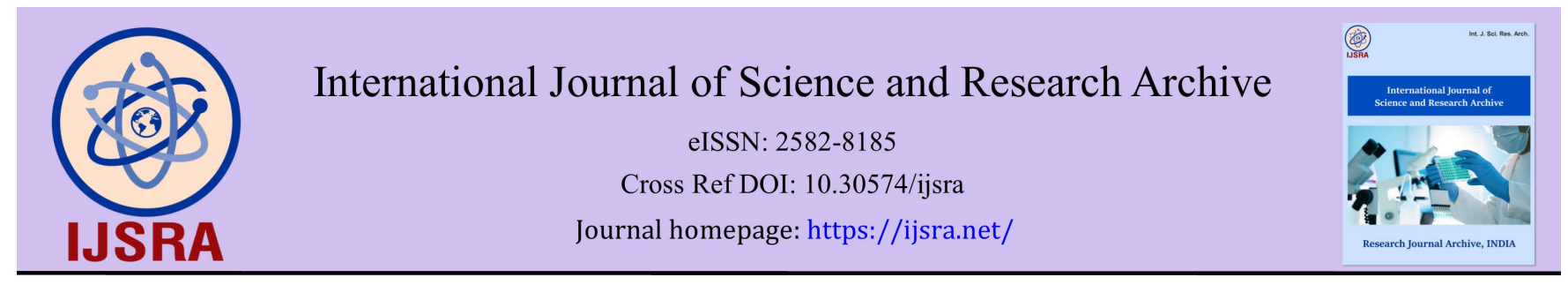

(REvieW ARTiCle)

\title{
The impact of workplace violence on nurses and nursing practice: A literature review
}

Omotola Adebayo 1, ${ }^{*}$, Julia Ugorji 2, Agatha Ekeh 3, Elsie Jolade 4, Ngozi Odoh 5, Angela Ikeme 6, Ngozi Azoroh 7 , Olatubosun Aloba ${ }^{8}$ and Grace Ogiehor-Enoma ${ }^{9}$

${ }^{1}$ Nurse practitioner, Geriatric and Extended Care service line, Home Based Primary Care, Atlanta VA Medical Center, Decatur, GA.

${ }^{2}$ North Hennepin Community College, Brooklyn Park, MN (NHCC).

${ }^{3}$ Adjunct Faculty (SONHP) University of San Francisco, CA (USFCA) 2130 Fulton Street, San Francisco, CA 94117.

${ }^{4}$ Clinical Professor, Hunter-Bellevue School of Nursing, City University of New York, New York

${ }^{5}$ Adjunct Faculty for DNPs/APRNs University of Central Florida College of Nursing, 12201 Research Pkwy Suite 300, Orlando, FL 32826.

${ }^{6}$ Santa Clara Valley Medical Center Hospitals \& Clinics 7475 Camino Arroyo Gilroy CA 95020.

${ }^{7}$ Adjunct Faculty University of the District of Columbia (UDC-CC) 801 North Capitol St NE, Washington, DC 20002.

${ }^{8}$ Women's Health Nurse Practitioner, PhD, WHNP. Wake County Health and Human Services, Raleigh NC 27610.

${ }^{9}$ Hunter-Bellevue School of Nursing, Hunter College, New York, NY.

International Journal of Science and Research Archive, 2022, 05(01), 051-058

Publication history: Received on 05 November 2021; revised on 18 December 2021; accepted on 20 December 2021

Article DOI: https://doi.org/10.30574/ijsra.2022.5.1.0203

\section{Abstract}

Aim: To understand workplace violence and its impact on nurses through literature review.

Background: Violence in mainstream society has permeated the workplace, especially the healthcare work environment. Violence against nurses from various sources and groups of people such as colleagues, clients/patients, and families/guests are on the rise. In their roles as Clinicians, nurses require a healthy work environment to achieve effective positive patient outcomes. Understanding the impact of workplace violence against nurses becomes paramount.

Method: Comprehensive searches were conducted using scholar search engines to identify published articles on workplace violence affecting nurses. Articles were appraised and validated. The studies varied in design from randomized to nonrandomized, longitudinal, and cohort.

Results: The literature suggests that nurses are exposed to various types of workplace violence, which can be physical, psychological, verbal abuse, and other threats.

Conclusion: Given the limited literature on workplace violence especially on nurses and how to support them, further research is required on this subject.

Implications for Nursing Management: Healthcare delivery in the $21^{\text {st }}$ century demands that nursing leadership make a dedicated effort to nurture a healthy work environment in support of nurses' positive outcomes, intensify advocacy and formulate policies to address workplace violence against nurses

Keywords: Healthcare violence; Physical violence; Workplace violence; Gender violence; Aggression; Nursing; Injury

\footnotetext{
${ }^{*}$ Corresponding author: Omotola Adebayo

Nurse practitioner, Geriatric and Extended Care service line, Home Based Primary Care U.S. Department of Veteran Affairs 1670 Clairmont Road, Decatur GA 30033.
}

Copyright (@ 2022 Author(s) retain the copyright of this article. This article is published under the terms of the Creative Commons Attribution Liscense 4.0. 


\section{Introduction and Background}

Violence in mainstream society has permeated the workplace, especially the healthcare work environment. According to Arnetz et al. [1] and Jakobsson, Axelsson, and Ormon [ 2] the occurrence and impact of Workplace Violence (WPV) are on the rise around the world. In the United States of America (USA), violence against nurses is a rampant occurrence and deserves proper attention and intervention. Jatic et al. [3] noted that the incidents of WPV and the impact are underreported because of limited information. The severity of the problem may be unknown. Among the frontline healthcare workers, nurses are most negatively affected, adding to the decline of willing nurses to continue to practice nursing [3].

Violence in the healthcare environment against nurses is from various sources and groups of people such as colleagues, clients/patients, and families/guests of patients (see table 1). Effects of violence leave indelible marks on the victim. Certain high-impact workspaces like the emergency and mental health care units in the hospital predispose nurses to experience many types of violence while working [1]. Different forms of violence perpetrated against nurses include physical, psychological, verbal, sexual, and financial (see table 2). The resulting problems caused by Workplace Violence include psychological and health issues, a hostile work environment, low productivity, and loss of profit. Many nurses experience direct or indirect violence in the form of stalking, threats/harassment, door slamming, table banging, object throwing, assault, punching, scratching, property damage and theft, slander, yelling, swearing, and intimidation [3].

Table 1 Associated cause of Workplace Violence

\begin{tabular}{|l|c|c|c|c|}
\hline Author & \multicolumn{4}{|c|}{ Perpetrators of Violence } \\
\hline & Patients & Guests & Colleagues & Supervisors \\
\hline Chaiwuth et al., (2019) & $34.7 \%$ & $44.8 \%$ & & \\
\hline Cheung \& Yip (2017) & $36.6 \%$ & $17.5 \%$ & $7.7 \%$ & $6.3 \%$ \\
\hline Fasanya \& Dada, (2015) & $53.5 \%$ & $15.5 \%$ & $18.3 \%$ & $12.7 \%$ \\
\hline
\end{tabular}

According to the Occupational Safety and Health Administration [OSHA], violence is categorized into four groups: Type- I, II, III, and IV. Type I violence is associated with criminal intent. Type II involves violence by a customer or client. Type III violence involves actions between persons familiar with each other such as colleagues at work. Type IV violence is usually between people who have a close relationship, as in domestic violence (DV). Type V violence is considered ideological and is usually perpetrated against organizations due to differences in points of view. Nurses tend to suffer Types II and III forms of violence.

Table 2 Types of Violence

\begin{tabular}{|l|c|c|c|c|}
\hline Author & Physical & Verbal & Sexual & Psychological \\
\hline Pienet al., (2018) & & $60 \%$ & & $60 \%$ \\
\hline Jacobsson et al., (2020) & $26.7 \%$ & $50 \%$ & & $65.5 \%$ \\
\hline Jatic et al., (2019) & $74.2 \%$ & $89.2 \%$ & $30.1 \%$ & $86.9 \%$ \\
\hline Chaiwuth et al., (2019) & $12.1 \%$ & $50.3 \%$ & & \\
\hline
\end{tabular}

Violence in any form is unacceptable. There is a need to identify areas to be investigated for in-depth analysis of the problem and provide appropriate solutions. Interventions to prevent or manage violence will be key to providing a violence-free work environment for healthcare workers like nurses. This literature review aims to create awareness about violence and its impact on nurses and nursing practice. 


\section{Theoretical/Conceptual Framework}

The National Institute for Occupational Safety and Health / National Occupation Research Agenda (NIOSH / NORA) model is used to guide this review. The Occupational Safety and Health Act of 1970 established NIOSH as a research agency focused on the study of worker safety and health and empowering employers and workers to create safe and healthy workplaces. The National Occupation Research Agenda is a partnership program that inspire new research and improved workplace practices. The National Institute for Occupational Safety and Health theorizes that work organization and culture influence occupational hazards and illness. Incorporating violence prevention policies and procedures, such as the orientation of new hires and periodic training of all staff, can have a far-reaching reduction effect on the occurrence of violence in the workplace. The national strategy for Prevention through Design (PtD) is a program that supports the National Institute for Occupational Safety and Health and the National Occupation Research Agenda. The Prevention through Design emphasizes designing a work environment to minimize hazards and risks of violence as opposed to managing them after they occur.

\section{Methods}

A literature search was performed to identify relevant publications in English language. The Cumulative Index of Nursing and Allied Health Literature [CINAHL], Google Scholar, ProQuest, PsychInfo, and PubMed databases were explored and yielded 155 articles. Forty-six peer-reviewed articles were deemed applicable to the subject matter. Nineteen of the 46 articles were selected and systematically appraised for inclusion. Selection criteria included journals and articles written within the last ten years and focusing on the topics addressing workplace violence among nurses in the healthcare setting. Articles were appraised and validated to include randomized, longitudinal, and cohort studies

\section{Results and discussion}

Most of the studies were conducted outside of United States (see table 3).

Table 3 Workplace Violence Demographic Characteristics Table

\begin{tabular}{|l|l|l|}
\hline Author & Date & Country \\
\hline Arnetz et al., & 2017 & United States \\
\hline Basfr et al., & 2019 & Saudi Arabia \\
\hline Chaiwuth et al., & 2019 & Thailand \\
\hline Faflioraa et al., & 2016 & Greece \\
\hline Cheung \& Yip, & 2017 & Hong Kong \\
\hline Jacobbson et al., & 2020 & Sweden \\
\hline Jatic et al., & 2019 & Bosnia \\
\hline Liu et al., & 2020 & China \\
\hline Serafin et al., & 2019 & Poland \\
\hline Tiruneh et al., & 2016 & Ethiopia \\
\hline Turk et al., & 2018 & Turkey \\
\hline
\end{tabular}

This review result suggests that WPV against healthcare workers, especially nurses, is prevalent and has reached pandemic proportions. Serious consequences were reported in most of the cases of workplace violence studied by Lu et al. [4]. The random effects model was used to analyze 47 studies. Exploration of WPV among 81,771 healthcare professionals in China found the prevalence of workplace violence against healthcare professionals appears to be a significant issue in China, ranging from $31.1 \%$ to $87.8 \%$. 
Workplace violence reduces employee morale, which consistently lessens employees' work performance, increases levels of stress, anxiety, depression, and irritability [5].

Examining whether work environment conditions moderate the mediating effect that burnout has on the relationship between workplace violence and musculoskeletal injury, anxiety, and sleep disturbance outcomes (Havaei, Astivia, \& MacPhee [6] found ( $\mathrm{r}=0.33, \mathrm{p}<.01)$, anxiety $(\mathrm{r}=0.44, \mathrm{p}<.01)$, and sleep disturbances ( $\mathrm{r}=0.37, \mathrm{p}<.01)$. Emotional exhaustion was also positively related to three health outcomes. The indirect effect of workplace violence on musculoskeletal injuries (R2=14\%, Sobel $\mathrm{Z}=4.30, \mathrm{p}<.001$ ) (b) anxiety disorders(R2 $=34 \%$, SobelZ $=8.30, \mathrm{p}<.001$ ), and (c) sleep disturbances (R2=24\%,So- belZ=7.25,p<.001) was mediated through the mechanism of emotional exhaustion.

In another study, Liu et al. [7] used a questionnaire to collect data from 1502 nurses from a Chinese hospital system. The study found nurse-reported workplace violence was associated directly with higher incidences of burnout, less job satisfaction, lower patient safety, and more adverse events. The study results showed that when workplace safety was improved, job satisfaction and lower levels of burnout were noted.

Basfr et al. [8] aimed to measure the prevalence of workplace violence in psychiatric hospitals in Suadi Arabia. There were 310 participants in the study who completed questionnaires that explored aspects of workplace violence. The data result indicated that $90.3 \%$ of the nurses admitted having experienced workplace violence, of which $57.7 \%$ had been exposed to both physical and verbal abuse. Stress and depression were noted among the affected nurses after their experiences. The recommendation was made for investment in therapy and prevention of workplace violence.

Pien et al. [9] looked to find any associations between different workplace violence sources and health outcomes in nurses. In this cross-sectional study with 1,690 female nurses, a self-administered questionnaire was used to examine the nurses' experiences with workplace violence, breaking it down into categories like physical, psychological, verbal, and sexual. In the questionnaire, the source of the violence, internal or external, was also examined. The study found that Sixty percent of the internal workplace violence was psychological and verbal. Adverse psychosocial work conditions were associated with workplace violence. After adjustment for demographic characteristics and psychosocial work conditions, internal workplace violence resulted in higher risks of poor self-rated health and mental health than external workplace violence. The study found that internal violence had a more profound impact on nurses than external and that measures should be employed by hospitals to address it.

The study of workplace violence toward nurses in Hong Kong by Cheung and Yip [10] found that perpetrators of workplace violence include: patients (36.6\%), relatives (17.5\%), colleagues (7.7\%), and supervisors (6.3\%). Another study of bullying in the workplace among Polish nurses by Serafin et al. [11] found that bullying was experienced by $65.84 \%$ of participants. Tiruneh et al. [12] found the prevalence of workplace violence and associated factors among nurses in northwest Ethiopia to be $26.7 \%$.

Fasanya and Dada [13] assessed the perspectives of nurses and certified nursing assistants (CNAs) in long-term medical care facilities on workplace violence to analyze caregivers' responses on workplace violence in long-term medical care facilities to identify common perpetrators of WPV and types of WPV practices in long-term medical care facilities. Data revealed that $65 \%$ of the participants had experienced WPV, while $41 \%$ believed that management shows little or no concern for their safety. In a survey by Ward-Smith, Hawks, Quallich, and Provance [14] to allow members of the Society of Urologic Nurses and Associates (SUNA) to describe their experience with respect to workplace incivility from a peer (lateral incivility), workplace incivility was described by $25.3 \%$ of the study population as severe enough for them to be planning to leave their present position within the next 12 months. Faflioraa et al. [15] while assessing workplace violence from three different Greek healthcare settings, a personal experience of workplace violence was reported by $76.3 \%$ of the nurses; among these, $78.7 \%$ reported being victimized over the last 12 months. The most frequent sites of violent incidents were the emergency department (40.6\%) and the hospital wards (40.6\%).

In a randomized study, Marquez et al. [16] examined employees' perceptions of organizational safety post workplace violence intervention and evaluations based on workplace exposure status. Questionnaires were used to capture organizational safety perceptions and violence exposure of employees from 41 hospitals. Three hundred and forty-three (343) employees completed the questionnaires. The study result showed that employees in the intervention units reported a more positive perception of organizational safety compared to employees in the control units. Employees in the intervention unit who experienced patient- employee workplace violence reported significantly more positive perceptions of organizational safety than those who experienced employee-employee workplace violence. 
Splelten et al. [17] in a systematic review of seven studies of 398 nursing home residents and 597 psychiatric patients, focused on the prevention of aggression by the aggressor in the pre-aggression phase. The review focus was to assess if organizational interventions aimed at preventing workplace aggression towards healthcare workers are effective in preventing or minimizing patients' and patient's advocate's aggression towards health care workers. Noted was a mixed result of very low to low-quality evidence that interventions focused on the vector during the pre-event phase, the event phase, or both, may result in a reduction of overall aggression and inconsistent low-quality evidence for multicomponent interventions. The recommendation was that more randomized controlled trials (RCT) studies that include employees as participants to improve the evidence-based studies are needed. The authors also concluded that standardizes outcome is urgently needed.

In a descriptive research study done in a tertiary hospital in Upper Northern Thailand by Chaiwuth et al. [18] 555 registered nurses were examined regarding the prevalence of workplace violence and risk factors among RNs working in a hospital. A standardized Workplace Violence Questionnaire Tool developed by International Labour Office (ILO), International Council of Nurses (ICN), World Health Organization (WHO) and Public Services International (PSI) in 2003 was used in data collection. Results showed that $84.0 \%$ of the nurses were worried about workplace violence towards them, 50.3\% reported experience verbal abuse, while $12.1 \%$ experienced physical abuse. Forty-four percent (44.8\%) of the perpetrators of the abuse were clinical nurses, followed by $34.7 \%$ of patients and patient's relatives. Chaiwuth et al. [18] noted that their finding was consistent with other studies that more than $50 \%$ of nurses have experienced violence in the workplace. Therefore, the call for providing a safe work environment for nurses, education on prevention and management of aggressive behavior in the workplace and providing mentorship for new and young nurses is needed.

Turk et al. [19] conducted a descriptive study among 200 healthcare professionals to evaluate the violence among healthcare professionals working in Kars province, Turkey. A 17- item questionnaire prepared by the researchers was used for data collection. Result showed $48.5 \%$ of participants stated that they witnessed violence, $61.5 \%$ were exposed to violence, $49.9 \%$ were exposed to violence in the form of insult, $91.1 \%$ of the violence perpetrators were male, $86.1 \%$ of the violence perpetrators were patient relatives, $70.7 \%$ of the professionals stated that no procedure was administered after the violence, $81.3 \%$ were exposed to the verbal violence most recently, $52.0 \%$ were exposed to violence in the service, and $99.0 \%$ expressed that the institution remained unresponsive to violence. The study concluded that healthcare professionals are in the group at high risk for violence exposure.

Arnetz et al. [1] conducted a prospective randomized controlled intervention study among 15,000 employees from multi-sites of seven hospitals in the Midwest of United States, covering 42 units and various specialties. The study spanned over five years and aimed to evaluate the impact of intervention in decreasing Type Two (lateral Violence) patient-worker violence and injury. A decrease in violence was noted within the first six months in the intervention group due to de-escalating intervention actions. However, by 12-24 months, there was no difference in the control and intervention groups. There was increased awareness of the issue because of stakeholder participation. However, $88 \%$ of under-reporting was noted.

Using a cross-sectional study method, Jatic et al. [3] looked at understanding the associated factors, frequency, and forms of violence in seven primary health care services in a public hospital in Sarayvo, Bosnia Herzegovina among 983 health professionals (323 Medical Doctors and 660 Nurses). Data indicated various forms of violence experienced by the participants, including sexual Violence, Verbal Abuse, Phone, Mail, and Threat, Slander, door slamming, Object Throwing, Table Banging, Property Theft and Damage, Injury, Stalking, and Weapon Attack. The result showed that $90.3 \%$ of the participants experienced workplace violence, $43.5 \%$ suffering more than one form of violence. Most notable are the following: Verbal violence-89.2\%-occurring most frequently at $87.5 \%$ than other forms. Object throwing and Indirect Physical abuse registered $74.2 \%$ and $74.7 \%$, respectively. Stalking was 30.1\%, and Rude Behavior occurred $86.9 \%$ of the experiences. It was noted that some abuse could be gender-based as the female professionals experienced more verbal abuse and stalking, especially in the urban settings. $62 \%$ of the participants worked in urban areas, and $84.4 \%$ were females, $67.5 \%$ were nurses. Working in an isolated environment like an outpatient clinic was considered a contributing factor.

Associated consequences of workplace violence include stress, insomnia, decrease morale and concentration, fear, avoidance behavior, decrease work satisfaction and increase use of sick leave. Some disorders associated with workplace Violence are Post Traumatic Stress Disorder (PTSD), Burnout, and Anxiety. It is questionable if gender difference impacted the processing and reporting of violence. Further study is needed to understand why females may over-report the male's under-report cases of violence. 
In a qualitative study in Sweden by Jacobsson et al. [2] the kinds of violent experiences of healthcare workers in a University Hospital (Surgical Ward) and how they are managed were analyzed. Four main themes were identified, namely- (a) Characteristics of workplace violence, (b) Predictability of violence, (c) Consequences associated with violence, and (d) Management approach or lack thereof. Fifty percent (50\%) of participants experienced Verbal Abuse, 26.7\% suffered Physical Violence, and 65.5\% experience non-physical violence such as rude remarks.

Examples of workplace violence were identified as (a) Physical (punching, kicking, pushing, pinching, scratching, spitting, and object throwing), (b) Verbal-most commonly related to dissatisfaction in the care provided and includes yelling, swearing, threat, intimidation- showing of the knife, blocking the door, following to place of residence, degradation of professional performance, (c) Sexual Harassment (inappropriate touch, suggestive sexual statement, chasing, and grabbing), and (d) Property damage as in window breaking, (p.3).

The result showed that those who work in the Emergency Department, Paramedics, and Psychiatric department are mostly at risk due to the type of patient populations in these hospital departments. Patients in these areas of health care tend to suffer dementia, delirium due to situations like recovery from surgical anesthesia, opioid, pain, alcohol, and exposure to lethal gun violence, and presence of security/police. The staff rationalized why the incidents occurred as unintentional, though the actions remained impactful. The identification of some of these disease processes as a potential source of violence led to some form of predictability of violence, yet there was no provision of guidelines for proper intervention. The negative consequences of the violence reached the health care workers, patients involved, families, and other innocent patients. The Nurses felt hopeless, vulnerable, exposed, and unprotected (p. 6), resulting in insomnia, fear, increase in ill health, decrease quality of care (p.1), and stress leading to increase sick calls and professional self-doubt. The care provided seems compelled due to fear of what the patients and their families may do to the caregivers. There were medication errors due to distraction.

\section{Conclusion}

Understanding the impact of workplace violence in nursing is very important to the nursing discipline. Nurses as professionals, function in different roles, including but not limited to educators, researchers, clinicians, providers, and case managers. Nursing has a pertinent role in assessing, diagnosing, and planning interventions based on the needs of the individual. A component of the assessment involves a thorough understanding of the environmental situation in which care will take place. The study findings suggest that workplace violence against nurses has reached pandemic proportions with severe, lasting impact. Nurses experience lasting negative health outcomes from violence exposure, including burnout, depression, anxiety disorders, sleep disturbances, post-traumatic stress disorder (PTSD), and psychosomatic disorders. Social and economic costs due to increased absenteeism are other major adverse consequences of workplace violence (see table 4).

Table 4 A Synthesis of Effects of Workplace Violence

\begin{tabular}{|l|c|c|c|c|c|c|}
\hline Author & Stress & Anxiety & Burnout & Depression & $\begin{array}{l}\text { Ill } \\
\text { Health }\end{array}$ & $\begin{array}{l}\text { Less } \\
\text { Satisfaction }\end{array}$ \\
\hline Basfr et al., (2019) & $\uparrow$ & & & $\uparrow$ & & \\
\hline Havaei, Astivia, \& Macphee, (2020) & $\uparrow$ & $\uparrow$ & $\uparrow$ & & $\uparrow$ & \\
\hline Liu et al., (2020) & & & $\uparrow$ & & & $\uparrow$ \\
\hline Rasool et al, 2020 & $\uparrow$ & $\uparrow$ & & $\uparrow$ & $\uparrow$ & \\
\hline
\end{tabular}

\section{Implications for Nursing Management}

Nursing education programs should include instructions about the issues identified as workplace violence. Psychosocial needs, as well as physical symptoms of the workplace violence should be included as part of nursing training programs. A proper reporting process should be part of professional development. Knowledge gained from this inquiry will enable nurse managers to develop guidelines and protocols to manage issues from workplace violence in nursing. This review will increase the awareness of clinicians to incorporate the factors that lead to workplace violence in nursing as part of their educative nursing system. In addition, nurses are involved in quality improvement as case managers in the hospitals, and therefore, this knowledge is significant. The value added by identifying these factors will serve as building knowledge for nursing practice in a safe working environment. At the 
individual level, the nurse managers will assist the individual nurses in determining the personal impacts that the violence has contributed to their wellbeing. Nurses can incorporate the findings for future research, which can be used to promote awareness. Nurses, as healthcare leaders, advocate for the appropriative management of workplace violence. There is a great need for organizational interventions such as developing relevant policies and procedures related to WPV and providing adequate training, education, and support to implement violence management policies to ensure safety at the workplace.

\section{Compliance with ethical standards}

\section{Acknowledgments}

Special thanks to the leadership of the National Association of Nigerian Nurses in North America (NANNNA) and the NANNNA Education Committee for their support.

\section{Disclaimer}

The views expressed in this article are those of the authors and do not necessarily reflect the position or policy of the Department of Veterans Affairs or the United States government.

\section{Disclosure of conflict of interest}

The authors declare no conflict of interest.

\section{Funding support}

No funding support for the publication of this article.

\section{Statement of ethical approval}

This literature review was based on existing literature.

\section{References}

[1] Arnetz JE, Hamblin L, Russell J, Upfal MJ, Luborsky M, Janisse J, Essenmacher L. Preventing Patient-to-Worker Violence in Hospitals: Outcome of a Randomized Controlled Intervention. Journal of occupational and environmental medicine. 2017; 59(1): 18- 27.

[2] Jakobsson J, Axelsson M, Ormon K. "The Face of Workplace Violence: Experience of Healthcare Professionals in Surgical Hospital Wards, “Nursing Research and Practice. 2020, ArticleID 185438710.

[3] Jatic Z, Erkocevic H, Trifunovic N, Tatarevic E, Keco A, Sporisevic L, Hasanovic E. Frequency and Forms of Workplace Violence in Primary Health Care. Medical archives (Sarajevo, Bosnia and Herzegovina). 2019; 73(1): 6-10.

[4] Lu L, Dong M, Wang SB, Zhang L, Ng CH, Ungvari GS, Li J, Xiang YT. Prevalence of workplace violence against health-care professionals in China: a comprehensive meta-analysis of observational surveys. Trauma, Violence, \& Abuse. 2020 Jul;21(3):498-509.

[5] Rasool SF, Wang M, Zhang Y, Samma M. Sustainable work performance: the roles of workplace violence and occupational stress. International journal of environmental research and public health. 2020 Jan;17(3):912.

[6] Havaei F, Astivia OL, MacPhee M. The impact of workplace violence on medical-surgical nurses' health outcome: A moderated mediation model of work environment conditions and burnout using secondary data. International journal of nursing studies. 2020 Sep 1;109:103666.

[7] Liu J, Zheng J, Liu K, Liu X, Wu Y, Wang J, You L. Workplace violence against nurses, job satisfaction, burnout, and patient safety in Chinese hospitals. Nursing Outlook. 2019; 67(5): 558-566.

[8] Basfr W, Hamdan A, Al-Habib S. Workplace Violence Against Nurses in Psychiatric Hospital Settings: Perspectives from Saudi Arabia. Sultan Qaboos University Medical Journal [SQUMJ]. 2019; 19(1): 19. 
[9] Pien L-C, Cheng Y, Cheng W-J. Internal workplace violence from colleagues is more strongly associated with poor health outcomes in nurses than violence from patients and families. Journal of Advanced Nursing. 2018; 75(4): 793-800.

[10] Cheung T, Yip PS. Workplace violence towards nurses in Hong Kong: prevalence and correlates. BMC public health. 2017; 17(1); 196.

[11] Serafin LI, Czarkowska-Pączek B. Prevalence of bullying in the nursing workplace and determinant factors: a nationwide cross-sectional Polish study survey. BMJ open. 2019; 9(12): e033819.

[12] Tiruneh BT, Bifftu BB, Tumebo AA, Kelkay MM, Anlay DZ, Dachew BA. Prevalence of workplace violence in Northwest Ethiopia: a multivariate analysis. BMC nursing. 2016; 15: 42.

[13] Fasanya BK Dada EA. Workplace Violence and Safety Issues in Long-Term Medical Care Facilities: Nurses' Perspectives Safety and Health Work 2016; 7: 97e101.

[14] Ward-Smith P, Hawks JH, Quallich SA, Provance J. Workplace incivility: Perceptions of urologic nurses. Urologic Nursing. 2018; 38(1): 20-26.

[15] Faflioraa E, Bampalisa BG, Zarlasb G, Sturaitisb P, Lianasb D, Mantzouranis G. Workplace violence against nurses in three different Greek healthcare settings. Work. 2016; 53: 551-560.

[16] Marquez SM, Chang CH, Arnetz J. Effects of a workplace violence intervention on hospital employee perceptions of organizational safety. Journal of occupational and environmental medicine. 2020 Dec;62(12):e716.

[17] Spelten E, Thomas B, O'Meara PF, Maguire BJ, FitzGerald D, Begg SJ. Organisational interventions for preventing and minimising aggression directed towards healthcare workers by patients and patient advocates. Cochrane Database of Systematic Reviews. 2020(4).

[18] Chaiwuth S, Chanprasit C, Kaewthummanukul T, Chareosanti J, Srisuphan W, Stone TE. Prevalence and Risk Factors of Workplace Violence Among Registered Nurses in Tertiary Hospitals. Pacific Rim International Journal of Nursing Research. 2020 Sep 16;24(4):538-52.

[19] Turk R, Sakar T, Akca D. Evaluation of Violence Exposure of Healthcare Professionals Working in Kars Province. International Journal of Caring Sciences. 2018 May 1;11(2):1014-20. 